\title{
Spectrophotometric determination of acyclovir after its reaction with ninhydrin and ascorbic acid
}

\author{
Ukpe Ajima*, Johnson Ogoda Onah \\ Department of Pharmaceutical Chemistry, Faculty of Pharmaceutical Sciences, University of Jos, Jos, Nigeria.
}

\section{ARTICLE INFO \\ Article history: \\ Received on: 23/12/2014 \\ Revised on: 17/01/2015 \\ Accepted on: 14/03/2015 \\ Available online: 27/04/2015}

\section{Key words:}

Acyclovir, Ninhydrin,

Ascorbic acid,

Spectrophotometry,

Pharmaceutical analysis.

\begin{abstract}
Acyclovir is a purine-based nucleoside antiviral agent used in the management of Herpes simplex and other viral infections. The present study is aimed at developing and validating a simple and rapid spectrophotometric method for its determination. The mechanism of the proposed method is based on the condensation/coupling reaction between Acyclovir and Ninhydrin-Ascorbic acid at $\mathrm{pH}$ 5. A purple colored product with maximum absorption at $540 \mathrm{~nm}$ was assayed to quantitatively evaluate the drug content in the formulation. The calibration curve was found to be linear up to $30 \mu \mathrm{g} / \mathrm{ml}$. Analyte recovery tests carried out by the proposed method gave recovery of between $96.9-102.0 \%$. Molar absorptivity and Sandells' sensitivity were determined to be $41,071.43 \mathrm{~L} \mathrm{~mol}^{-1} \mathrm{~cm}^{-1}$ and $1.84 \mu \mathrm{g} \mathrm{cm}^{-2}$ respectively. The precision was assessed by determining the inter-day and intra-day variation which ranged between $1.45-1.63 \%$ and $0.81-1.12 \%$ respectively. The results show that the reaction produced a stable product and the proposed method is cost-effective and possesses adequate accuracy, precision and sensitivity. It can therefore be conveniently applied for the determination of acyclovir in dosage forms.
\end{abstract}

\section{INTRODUCTION}

Acyclovir (9-[(2-hydroxyethoxy)methyl] guanine) is a synthetic purine-based nucleoside analogue with potent in vitro and in vivo inhibitory activity against herpes simplex viruses (HSV), varicella zoster virus (VZV), epstein-Barr virus (EBV), cytomegalovirus (CMV) and human herpes virus 6 (HHV-6) (Corey et al, 1982; Keeney et al, 1982; Thin, 1988; Wagstaff et $a l, 1994)$. Acyclovir exerts its antiviral activity by acting as pseudo-substrate and thus inhibits viral DNA polymerase enzyme. Phosphorylation of Acyclovir to the active acyclovir monophosphate occurs via viral or cellular thymidine kinase enzyme constitute the preliminary reaction ( $\mathrm{O}^{\prime}$ Brien and Richards, 1989; Gnaan et al, 1983; Whitley et al, 1982). The British Pharmacopoeia (2005) specifies a UV spectrophotometric method for the determination of acyclovir. A number of unofficial assay methods utilizing a variety of techniques and reaction pathways have also been successfully developed for the

\footnotetext{
* Corresponding Author

Ukpe Ajima, Department of Pharmaceutical Chemistry, Faculty of

Pharmaceutical Sciences, University of Jos, Jos, Nigeria.

Email: descar84@yahoo.com
}

drug and some of these include; Polarography (Sheribah et al, 2009), Radioimmunoassay (Blum et al, 1982; Quin et al, 1979), Near IR spectroscopy ( $\mathrm{Yu}$ and Xiang, 2008), Microcellar electrokinetic chromatography (Yeh et al, 2006), HPLC with UV detection (Batterman et al, 1998; Pramar et al, 1990; Dubhashi and Vavia, 2000; Land and Bye, 1981), HPLC with MS detection (Kourany and Cyr, 1995; Kamel et al, 1999), HPLC with flourimetric detection (Testereci et al, 1998; Macka et al, 1993; Mascher et al, 1992; Jankowski et al, 1998). Acyclovir determination in pharmaceutical products has also been performed by employing methods based on derivatization of the drug with chromogenic reagents (Basavaiah and Prameela, 2002; El-din et al, 2006; Sultan, 2003; Mustafa et al, 2004; Chakraborty et al, 2011). A derivative (Daabees, 1998) and a differential spectrophotometric method (Mahrous et al, 1992) have also been reported. Spectrophotometric methods continue to be the most preferred for routine analytical work due to their simplicity, reasonable level of sensitivity and their low cost. Some of the previously mentioned colorimetric methods have some limitations such as long reaction time and low selectivity for the analyte. The present study therefore aims to develop a simple and accurate colorimetric method for the determination of acyclovir in dosage form. 


\section{EXPERIMENTAL}

\section{Materials}

Acyclovir tablets were commercial products. The following reagents were obtained from BDH, England: ninhydrin, ascorbic acid, sodium hydroxide, ethanol, citric acid. All the chemicals and reagents used were of analytical grade and were used without further purification. The aqueous solutions were freshly prepared with triple distilled water. A Shimadzu UVVisible double beam spectrophotometer (Model 1250, Japan) was used for the measurements.

\section{Method}

\section{Extraction of Pure Acyclovir from Tablet Formulation}

Twenty (20) tablets of acyclovir (label claim: $400 \mathrm{mg}$ each) were finely powdered in a porcelain mortar and extracted with $0.5 \mathrm{MolL}^{-1}$ sodium hydroxide $(25 \mathrm{~mL} \mathrm{x} \mathrm{4).} \mathrm{This} \mathrm{was} \mathrm{followed}$ by filtration through Whatman no. 1 filter paper. The filtrate was then evaporated to dryness at reduced temperature. The residue was collected and weighed and its melting point determined to ascertain its purity. This powder was used subsequently as a pure secondary reference sample.

\section{Preparation of buffer solution (pH 5)}

$4.95 \mathrm{~g}$ of citric acid and $2.0 \mathrm{~g}$ of sodium hydroxide were dissolved in $100 \mathrm{~mL}$ distilled water and its $\mathrm{pH}$ was then adjusted to 5.0 with sodium hydroxide (Nagaraja et al, 2011).

\section{Preparation of 1\% w/v ninhydrin Solution}

$1.0 \mathrm{~g}$ of ninhydrin was weighed and dissolved in some ethanol in a $100 \mathrm{~mL}$ volumetric flask and the volume made up to mark (Arayne et al, 2008).

\section{Preparation of $0.1 \% \mathrm{w} / \mathrm{v}$ ascorbic acid solution}

$0.1 \mathrm{~g}$ of ascorbic acid was weighed and dissolved in some distilled water in a $100 \mathrm{~mL}$ volumetric flask and the volume made up to mark (Subbayamma and Rambabu, 2008).

\section{Preparation of acyclovir stock solution.}

$100 \mathrm{mg}$ of the pure drug was dissolved in $100 \mathrm{~mL}$ of 0.5 $\mathrm{MolL}^{-1} \mathrm{NaOH}$ in a volumetric flask to form the stock solution (1 $\mathrm{mg} / \mathrm{mL}$ ).

\section{Construction of calibration curve and its validation}

From the stock solution of acyclovir ( $1 \mathrm{mg} / \mathrm{mL}), 1.0-$ $3.0 \mathrm{~mL}$ were quantitatively transferred to separate $10 \mathrm{~mL}$ calibrated screw-cap test-tubes. $4.0 \mathrm{~mL}$ of the buffer solution $(\mathrm{pH}$ 5.0), $1.0 \mathrm{~mL}$ of $1 \% \mathrm{w} / \mathrm{v}$ ninhydrin solution and $0.5 \mathrm{ml}$ of $0.1 \% \mathrm{w} / \mathrm{v}$ ascorbic acid solution were added and shaken for three minutes. The volume in each tube was adjusted to $9.0 \mathrm{~mL}$ with distilled water and kept in a boiling water bath for 15 minutes; the tubes were then removed and chilled in ice water. The solution in each tube was finally made up to $10.0 \mathrm{~mL}$ with distilled water. The blank solution was prepared in a similar manner but without the drug. The absorption maximum was determined using the spectrophotometer. The limits of detection and quantification were estimated according to IUPAC rules $(\mathrm{LOD}=\mathrm{B}+3 \sigma / \mathrm{S}$ and $\mathrm{LOQ}=$ $\mathrm{B}+10 \sigma / \mathrm{S}$ where $\mathrm{B}$ is the value of sample blank solution, $\sigma$ is the standard deviation of 10 replicates of the blank, and $S$ slope of calibration curve). Quadruplicate preparations were made for each volume and their absorbances read with the spectrophotometer. The plot of absorption against concentration was obtained from the mean of five replicate determinations. The curve was validated by methods previously reported (Onah and Odeani, 2002). Molar absorptivity, Sandells' sensitivity, regression equations and standard deviations were also determined. The analytical technique was optimized by a method reported earlier (Onah and Ajima, 2011).

To study the accuracy of the proposed method, analyte recovery tests were carried out using the standard addition method. For these, known quantities of pure acyclovir were mixed with definite amounts of pre-analyzed formulation and the mixture was analyzed as previously described. The total amount of the drug was then determined and the amount of the added drug recovered was calculated by difference. Precision of the method was assessed by evaluating the inter-day and intra-day variation which were determined by replicate analysis $(n=5)$ of calibration standards at three different concentration levels, five times per day on five consecutive days. The stability of the product formed from the reaction was also evaluated over a period of days. As part of the preliminary method optimization studies, the reaction was carried out at several $\mathrm{pH}$ values ranging between 2 -11 to determine the effect of $\mathrm{pH}$ on absorbance of the product formed and to establish the optimal $\mathrm{pH}$ for the analytical procedure. Maximum absorbance and stability of the product formed was obtained at $\mathrm{pH}$ of 5 and this was used subsequently for the analysis.

\section{Determination of actual content of Acyclovir in different tablet formulations using the proposed method}

Five different brands of acyclovir tablet formulation were assayed using the developed method. For each brand, the contents of 20 tablets were weighed, ground into a fine powder. An accurately weighed portion of the powder equivalent to $100 \mathrm{mg}$ acyclovir was transferred into a $100 \mathrm{~mL}$ volumetric flask. $25 \mathrm{~mL}$ of distilled water was added and after some minutes of mechanical shaking, the suspension was made up to mark with the solvent. After filtration, suitable amounts of the filtrate were then taken and the same procedure was applied as described for the calibration curve. The content of each label claim was verified by comparing the concentrations obtained from the validated curves with the actual concentrations of the drug taken. Standard deviations were also calculated for each brand.

\section{RESULTS}

Acyclovir was found to react with ninhydrin and ascorbic acid to form a purple colored product which absorbs maximally at $540 \mathrm{~nm}$ (Fig 1). The purple colored solution was stable beyond 24 
hours. The limit of detection (LOD) and limit of quantitation (LOQ) (calculated using LOD $=3 \sigma /$ slope of calibration curve and LOQ $=10 \sigma /$ slope of calibration curve) were determined to be 0.3 $\mu \mathrm{g} / \mathrm{mL}$ and $0.8 \mu \mathrm{g} / \mathrm{mL}$ respectively.

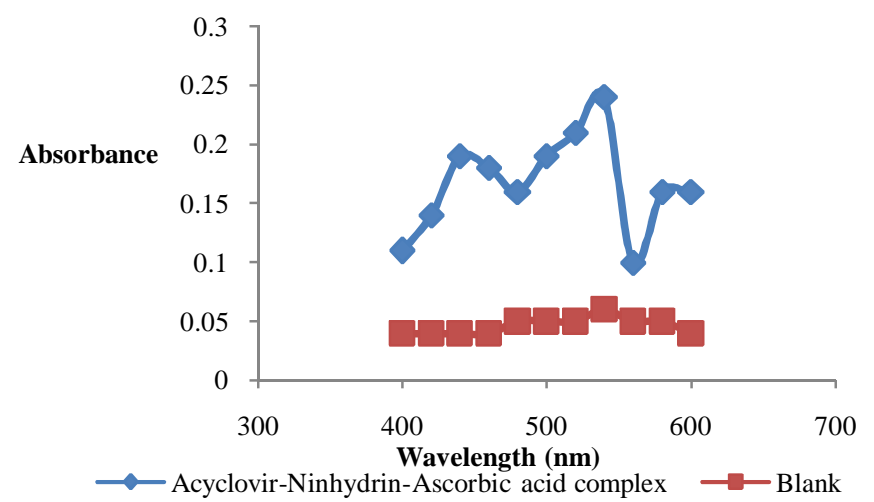

Fig. 1: Absorption spectrum for acyclovir-ninhydrin-ascorbic acid condensation product.

The plots of absorbance versus drug concentration were linear up to $30 \mu \mathrm{g} / \mathrm{mL}$. Optimization of the various concentrations during the experimentations did not show any significant differences in standard deviations $(p \geq 0.01)$ which suggests that the method produced consistent results. Several replicate determinations were carried out from which regression equations, standard deviations in slope and intercept were calculated. The regression equation shown in Equation 1 satisfied all the conditions investigated.

$\mathrm{A}_{\mathrm{abs}}=0.35 \mathrm{x}-0.062 \quad$ (regression coefficient $\left.=0.993\right) \ldots \ldots$ (1) where $\mathrm{A}_{\mathrm{abs}}=$ absorbance of analyte, $\mathrm{x}=$ concentration of analyte in the final mixture in moles.

Table 1: Results of recovery study using Standard addition method.

\begin{tabular}{|c|c|c|c|c|c|}
\hline $\mathrm{S} / \mathrm{n}$ & Brand & $\begin{array}{l}\text { Endogenous } \\
\text { Value } \\
(\mu \mathrm{g} / \mathrm{ml})\end{array}$ & $\begin{array}{l}\text { Pure } \\
\text { Acyclovir } \\
\text { added } \\
(\mu \mathrm{g} / \mathrm{ml})\end{array}$ & $\begin{array}{l}\text { Amount } \\
\text { Found } \\
(\mu \mathrm{g} / \mathrm{ml})\end{array}$ & $\begin{array}{l}\% \text { Recovery } \\
\pm \mathrm{SD}^{*}\end{array}$ \\
\hline \multirow{3}{*}{1.} & \multirow{3}{*}{ Hepirax $^{\circledR}$} & \multirow{3}{*}{10} & 5 & 14.91 & $99.4 \pm 1.16$ \\
\hline & & & 10 & 19.38 & $96.9 \pm 0.92$ \\
\hline & & & 15 & 24.80 & $99.2 \pm 1.63$ \\
\hline \multirow{3}{*}{2.} & \multirow{3}{*}{ Vivorax $^{\circledR}$} & \multirow{3}{*}{10} & 5 & 15.18 & $101.2 \pm 1.79$ \\
\hline & & & 10 & 20.14 & $100.7 \pm 0.88$ \\
\hline & & & 15 & 25.58 & $102.3 \pm 1.11$ \\
\hline \multirow{3}{*}{3.} & \multirow{3}{*}{ Zovirax $^{\circledR}$} & \multirow{3}{*}{10} & 5 & 14.91 & $99.4 \pm 2.07$ \\
\hline & & & 10 & 20.14 & $100.7 \pm 1.63$ \\
\hline & & & 15 & 25.50 & $102.0 \pm 1.54$ \\
\hline \multirow{3}{*}{4.} & \multirow{3}{*}{ Lovir $^{\circledR}$} & \multirow{3}{*}{10} & 5 & 15.02 & $100.1 \pm 1.24$ \\
\hline & & & 10 & 19.86 & $99.3 \pm 1.43$ \\
\hline & & & 15 & 24.78 & $99.1 \pm 1.95$ \\
\hline \multirow{3}{*}{5.} & \multirow{3}{*}{ Virest $^{\circledR}$} & \multirow{3}{*}{10} & 5 & 14.95 & $99.7 \pm 2.10$ \\
\hline & & & 10 & 19.98 & $99.9 \pm 1.66$ \\
\hline & & & 15 & 24.95 & $99.8 \pm 1.38$ \\
\hline
\end{tabular}

*Mean value of three determinations.

The results of the analyte recovery tests conducted by this method are shown in Table 1 . Recovery values were found to range between $96.9-102.0 \%$. The relative standard deviations of the slope and intercept were calculated to be $0.0412 \%$ and
$0.0158 \%$ respectively. Molar absorptivity and Sandells' sensitivity were similarly calculated to be $41,071.43 \mathrm{~L} \mathrm{~mol}^{-1} \mathrm{~cm}^{-1}$ and $1.84 \mu \mathrm{g}$ $\mathrm{cm}^{-2}$ respectively. The inter-day variation ranged between $1.45-$ $1.63 \%$ and the intra-day variation ranged from $0.81-1.12 \%$ for the method. The condensation product formed from the reaction was found to remain stable beyond 24 hours.

Table 2: Summary of validation parameters obtained for the method.

\begin{tabular}{ll}
\hline Parameter & Value \\
\hline Regression Equation & $\mathrm{Y}=0.35 \mathrm{x}-0.062$ \\
Correlation co-efficient $\left(\mathrm{r}^{2}\right)$ & 0.9930 \\
Range & $10-30 \mathrm{mcg} / \mathrm{ml}$ \\
Limit of detection (LOD) & $0.3 \mathrm{mcg} / \mathrm{ml}$ \\
Limit of quantitation (LOQ) & $0.8 \mathrm{mcg} / \mathrm{ml}$ \\
$\lambda_{\max }$ & $540 \mathrm{~nm}$ \\
Molar absorptivity & $41,071.43 \mathrm{~L} / \mathrm{mol} / \mathrm{cm}$ \\
Sandells sensitivity & $1.84 \mathrm{mcg} / \mathrm{cm}^{2}$ \\
Inter-day precision & $1.45-1.63 \%$ \\
Intra-day precision & $0.81-1.12 \%$ \\
\hline
\end{tabular}

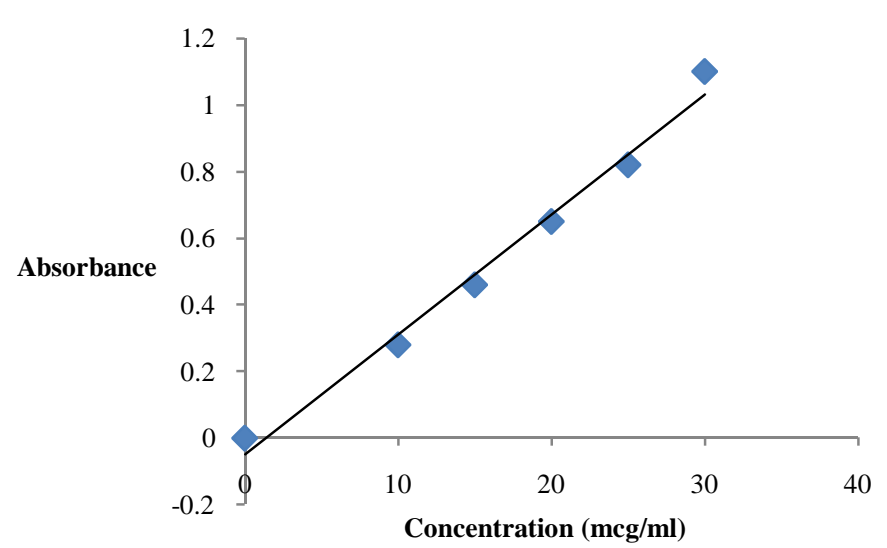

Fig. 2: Beer Lamberts plot of acyclovir-ninhydrin-ascorbic acid condensation product.

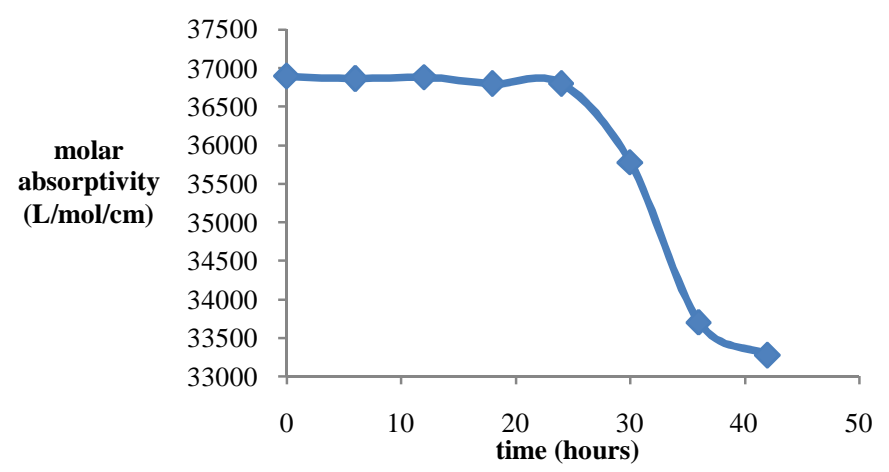

Fig. 3: Plot of molar absorptivity of the condensation product versus time.

\section{DISCUSSION}

The proposed method represents an analytical application for ninhydrin determination. Acyclovir possesses a primary amino group as part of the guanine residue which is capable of undergoing condensation and coupling reaction with ninhydrinascorbic acid (Figure 4) under acidic conditions created by the use of the citric acid buffer $(\mathrm{pH} 5)$ to produce a purple-coloured chromophore (Ruhemann's purple) that absorbs maximally at 
$540 \mathrm{~nm}$. This represents a bathochromic shift of the $\lambda \max$ for the drug, as it is established from literature that acyclovir absorbs only in the UV region with a $\lambda$ max of $255 \mathrm{~nm}$ (BP, 2005). Formation of the purple color serves as evidence of the reaction between acyclovir and the chromogenic reagents. Moore and Stein (1948) had previously shown that for ninhydrin reaction with primary amines, the $\mathrm{pH}$ must be maintained at 5 for optimum stability of the colored product.

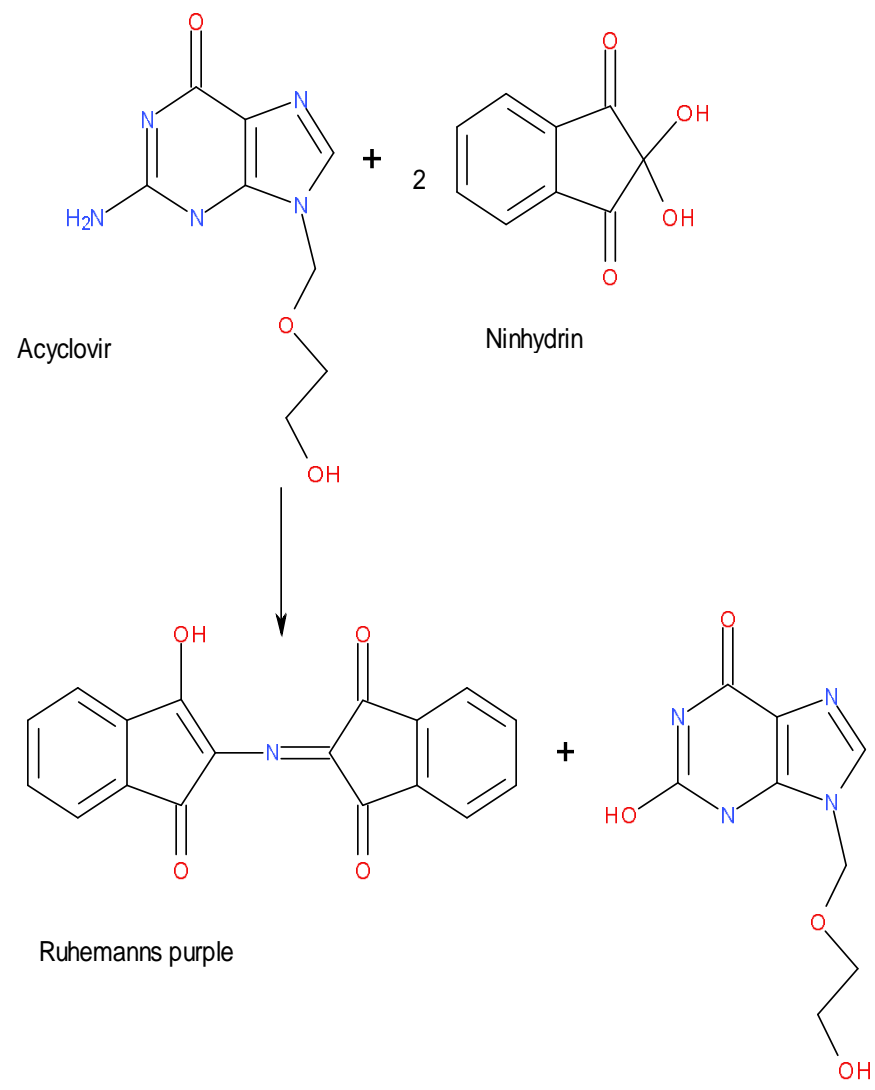

Fig. 4: Proposed reaction pathway between acyclovir and ninhydrin-ascorbic acid.

The stability of the product formed under the conditions mentioned above was therefore investigated. It was found that full color development occurred spontaneously at room temperature $\left(25 \pm 1{ }^{\circ} \mathrm{C}\right)$ and the values of absorbances of the product formed were found to remain unchanged after standing for 24 hours (figure 3) at room temperature indicating its stability for that period of time. The observation that a single equation (Equation 1) could be derived to satisfy the different reaction conditions reveals that the reaction produced stable products. The absorption spectrum for the acyclovir-ninhydrin complex showed two absorption maxima at $440 \mathrm{~nm}$ and at $540 \mathrm{~nm}$ as shown on figure 1 and this is as a result of the introduction of additional chromophores in conjugation with the existing chromophores sequel to the reaction.

The peak at $540 \mathrm{~nm}$ was chosen for the spectrophotometric measurements since it was more prominent indicating a higher intensity of absorption. Also, the high molar absorbtivity and relatively low Sandell's sensitivity provides evidence as to the accuracy and sensitivity of the technique. The high values of correlation coefficients obtained for regression equations demonstrate the good linearity of the method. As regards analytical applications, the proposed method was successfully applied for the quantitative determination of Acyclovir in five tablet formulations. The result obtained was in good agreement with the labeled claim.

\section{CONCLUSION}

The proposed method has been demonstrated to be quite simple, sensitive and reproducible and is thus suitable for the determination of Acyclovir alone and also in pharmaceutical dosage form. The method can thus be adapted for the quality control of Acyclovir in hospitals and laboratories in less endowed settings where more sophisticated analytical equipment such as HPLC is not readily available.

\section{ACKNOWLEDGEMENT}

This study was performed in the Pharmaceutical Chemistry Research Laboratory of the Department of Pharmaceutical Chemistry, University of Jos, Nigeria and the authors are grateful to the Department for equipment support.

\section{REFERENCES}

Arayne MS, Sultana N, Siddiqui FA, Mirza AZ and Zuberi MH. Spectrophotometric techniques to determine tranexamic acid: kinetic studies using ninhydrin and direct measuring using ferric chloride. J Mol Struct, 2008; 891: 475 - 480 .

Basavaiah K and Prameela HC. Simple spectrophotometric determination of acyclovir in bulk drug and formulations. Farmaco, 2002; 57: 443-449.

Battermann GCK, Heizenroeder S, Lubda D. HPLC analysis of active ingredients of pharmaceuticals. Labor Praxis, 1998; 30: 32-34.

Blum MR, Liao HTS and de Miranda P. Overview of Acyclovir Pharmocokinetic Disposition in Adults and Children. Ame J Med, 1982; 73:106-192.

Chakraborty R, Reddy SA, Sen S and Parameshappa B. Spectrophotometric determination and validation of Acyclovir. Arch Appl Sci Res, 2011; 3 (1):328-332

Corey L, Bendetti JK, Critchlow CW, Remington MR, Winter CA, Fahlander AL et al Blind Controlled Trial of Topical Acyclovir in Genital Herpes Virus Infections. Ame J Med, 1982; 73:326-334.

Daabees HG. The use of derivative spectrophotometry for the determination of acyclovir and diloxamide furoate in the presence of impurity or degradation product. Anal Lett, 1998; 31: 1509-1522.

Dubhashi SS and Vavia PR. Stability indicating reversed-phase HPLC method for acyclovir. Ind Drugs, 2000; 37: 464-468.

El-Din MK, El-Brashy AM, Sheribah ZA and El-Gamal RM. Spectrophotometric determination of acyclovir and ribavirin in their dosage forms. J AOAC Int, 2006; 89(3): 631-41.

Gnann JW, Barton NH and Whitley RJ. Acyclovir Mechanism of Action, Pharmacokinetics, Safety and Clinical Applications. Pharmacother, 1983; 3:275-283.

Jankowski A, Jankowska AL and Lamparczyk $\mathrm{H}$ Determination and pharmacokinetics of acyclovir after ingestion of suspension form J Pharm Biomed Anal, 1998; 18(1-2): 249-254

Kamel AM, Brown PR and Munson B. Effects of Mobile-phase Additives, Solution pH, Ionization Constant, and Analyte Concentration on the Sensitivies and Electrospray Ionization Mass Spectra of Nucleoside Antiviral Agents Anal Chem, 1999; 71: 5481-5492. 
Keeney RE, Kirk LE, and Bridgen, D. Acyclovir tolerance in human. Ame J Med, 1982; 73(A):176-181

Kourany E and Cyr TD. Determination of acyclovir (Zovirax) and guanine by microbore high-performance liquid chromatography with confirmation by atmospheric pressure chemical ionization mass spectrometry, Can J Appl Spectrosc, 1995; 40: 155-159.

Land G, and Bye A. Simple high performance liquid chromatographic method for the analysis of 9-[(2-hidrohsiethoxy)methyl] guanine (acyclovir) in human plasma and urine. J Chrom, 1981; 224: 5158.

Macka M, Borak J, Semenkova L, Popl M and Mikes V. Determination of acyclovir in blood serum and plasma by micellar liquid chromatography with Fluoremetric detection. J Chrom, 1993; 16(11):2359-2386.

Mascher H, Kikuta C, Metz R and Vergin H. New, highsensitivity high-performance liquid chromatographic method for the determination of acyclovir in human plasma, using Fluoremetric detection. J Chrom, 1992; 583: 122-127.

Mahrous MS, Abdel Khalek MM, Daabees HG and Beltagy YA. Use of differential spectrophotometry for determination of cytarbine and acyclovir in their dosage forms, Anal Lett, 1992; 25 1491-1501.

Moore S and Stein WH. Photometric ninhydrin method for use in the chromatography of amino acids J Biol Chem, 1948; 176: 367-388

Mustafa AA, Abdel-Fattah SA, Toubar SS and Sultan MA Spectrophotometric Determination of Acyclovir and Amantadine Hydrochloride through Metals Complexation, J Analyt Chem, 2004; 59(1): 33-38.

Nagaraja P, Shrestha AK, Shivakumar A and Al-Tayar NGS. Molybdate assisted ninhydrin based sensitive analytical system for the estimation of drugs containing amine group. J Food Drug Anal, 2011; 19 (1): $85-93$.

O' Brien J and Campoli-Richards J. Acyclovir, An updated review of its antiviral activity, Pharmocokinetic properties and therapeutic efficacy. Drugs, 1989; 37:233-309.

Onah JO and Ajima U. Quantitative analysis of Tenofovir by titrimetric, extractive ion-pair spectrophotometric and charge-transfer complexation methods. Trop J Pharm Res, 2011; 10 (1): 89-96

Onah JO and Odeani JE. Simultaneous spectrophotometric determination of sulphadoxine and pyrimethamine in pharmaceutical formulation. J Pharm Biomed Anal, 2002; 30: 851-857.

Pramar Y, Das Gupta V, Zerai T. Quantitation of Acyclovir in Pharmaceutical Dosage forms using High-Performance Liquid Chromatography . Drug Dev Ind Pharm, 1990; 16: 1687-1695.
Quin RP, de Mirandu P, Gerald L, and Good SS. A sensitive radioimmunoassay for the antiviral agent BW 248U (9-(2hydroxyethoxymethyl) guanine). Anal Biochem, 1979; 98:318-328.

Sheribah ZA, El-Brashy AM, El-Gamal RM. Stabilityindicating polarographic determination of acyclovir through chelation with nickel(II). J AOAC Int, 2009; 92 (2):419-27

Subbayamma AV and Rambabu C. Application of ninhydrin and ascorbic acid for the determination of cefpodoxime proxetil in pharmaceutical formulations. Oriental J Chem, 2008; 24 (2): 651 - 654.

Sultan M. Spectrophotometric determination of acyclovir in some pharmaceutical formulations. II Farmaco, 2003; 57(11): 865-870.

Testereci H, Dülger H, Ertekin A and Kahraman T. The determination of acyclovir in sheep serum, human serum, saliva and urine by HPLC. East J Med, 1998; 3 (2): 62-66.

The British Pharmacopoeia, 2005 Vol. II. Her Majesty Stationary Office, London.

Thin RN. Management of Genital Herpes Simplex Infections, Ame J Med, 1988; 85:3-6.

Wagstaff JA, Faulds D and Goa KL. Acyclovir: A reappraisal of its antiviral activity, Pharmocokinetic properties and therapeutic efficacy. Drugs, 1994; 47(1):153-205.

Whitley RJ, Blum MR, Barton $\mathrm{N}$ and de Mirande $\mathrm{P}$. Pharmocokinetics of acyclovir in humans following intravenous administration. A model for the development of parenteral antivirals. Ame J Med, 73:165-171, 1982.73: 176-181, 1982.

Yeh HH, Yang YH and Chen SH. Rapid determination of acyclovir in plasma and cerebrospinal fluid by micellar electrokinetic chromatography with direct sample injection and its clinical application. Electrophoresis, 2006; 27: 819-826.

$\mathrm{Yu} \mathrm{L}$ and Xiang B. Quantitative determination of acyclovir in plasma by near infrared spectroscopy. Microchem J, 2008; 90 (1): 63-66

\section{How to cite this article:}

Ajima U., Onah J. O. Spectrophotometric Determination of Acyclovir After its Reaction With Ninhydrin and Ascorbic Acid. J App Pharm Sci, 2015; 5 (04): 065-069. 